\title{
Sexual Harassment in the Information Age: The Human Resource Manager's Guide to Nontraditional Sexual Harassment ${ }^{1}$
}

Angelina C. Toomey and Allen F. Wysocki ${ }^{2}$

\section{Introduction}

With the globalization of American business, there has been a shift toward both technological advancement and equality in the workplace. These factors have helped to reveal an emerging type of inappropriate behavior known as new-age or nontraditional sexual harassment. "While male-female sexual harassment cases still predominate, same-sex and other forms of harassment are a growing trend. And often, there's no sex involved" (Schleifer 2007). The definition of sexual harassment has thus expanded to become much more comprehensive. Sexual harassment is not necessarily about sex but about power in relationships. Because of the broadened scope of such behavior, it is vital for human resource managers to be able to recognize these forms of harassment and understand ways to combat them.

\section{Revisiting the Meaning of Sexual Harassment and Its Implications}

What does the term "sexual harassment" mean? According to the U.S. Equal Employment Opportunity Commission (EEOC 2008), sexual harassment is defined denotatively as "unwelcome sexual advances, requests for sexual favors, and other verbal or physical conduct of a sexual nature when this conduct explicitly or implicitly affects an individual's employment, unreasonably interferes with an individual's work performance, or creates an intimidating, hostile, or offensive work environment."

While the definition of sexual harassment does not specify any gender, sexuality, or setting, the traditional interpretation is that sexual harassment refers to male-to-female harassment at the workplace. The term may be perceived this way because the statistical records do show mostly male-on-female harassment in traditional workplace settings. But the statistical records may not reflect reality because sexual harassment, especially in cases with male

1. This is EDIS document HR028, a publication of the Food and Resource Economics Department, Florida Cooperative Extension Service, Institute of Food and Agricultural Sciences, University of Florida, Gainesville, FL. Published December 2009. Please visit the EDIS Web site at http://edis.ifas.ufl.edu.

2. Angelina C. Toomey, Extension 4-H agent, Broward County, Davie, FL, and Allen F. Wysocki, associate professor, Food and Resource Economics Department, Florida Cooperative Extension Service, Institute of Food and Agricultural Sciences, University of Florida, Gainesville, FL.

Contact information for the authors: Angelina Toomey (954) 370-3725, and Allen Wysocki (352) 392-1826, extension 403.

The Institute of Food and Agricultural Sciences (IFAS) is an Equal Opportunity Institution authorized to provide research, educational information and other services only to individuals and institutions that function with non-discrimination with respect to race, creed, color, religion, age, disability, sex, sexual orientation, marital status, national origin, political opinions or affiliations. U.S. Department of Agriculture, Cooperative Extension Service, University of Florida, IFAS, Florida A. \& M. University Cooperative Extension Program, and Boards of County Commissioners Cooperating. Millie FerrerChancy, Interim Dean 
victims, goes largely unreported. In 2006, the EEOC received 12,025 charges of sexual harassment. Only $15.4 \%$ of these charges were filed by males (EEOC 2008), which was actually an all-time high.

Unless they are successful in reporting harassment and getting their situations resolved, victims of sexual harassment are left feeling embarrassed, helpless, or fearful. Unresolved cases of sexual harassment can demoralize the targeted employee, his or her coworkers, and management, and it can lead to decreased workplace productivity.

Sexual harassment between employees can happen anywhere, anytime. It can occur in the office, at lunch, or even via the Internet (United States Army Combined Arms Support Command, N.D.). It is the responsibility of management to accept and understand the definition of sexual harassment in order to effectively prevent this workplace behavior across various settings.

\section{Sexual Harassment Today}

Our understanding of what constitutes sexual harassment continues to broaden. Human resource managers must be able to recognize and understand the three major types of nontraditional sexual harassment.

\section{Female-Male Sexual Harassment}

Since its inception, Title VII of the Civil Rights Act of 1964 has included both male-female and female-male sexual harassment. In traditional male-female harassment, harassment can be verbal, physical, or visual. Sexual harassment claims filed by men are often fewer than claims by women. Males are more likely to feel flattered by female sexual attention in the workplace than are women in similar scenarios with men (Gross 1995). Also, men may be reluctant to voice their concerns based on stereotypes and social norms.

\section{Same-Sex Sexual Harassment}

In 1998, the U.S. Supreme Court held that same-sex (same gender) harassment is unlawful (Zachary 1999). Same-sex sexual harassment can be verbal, physical, or visual. It should be noted by human resource managers that same-sex sexual harassment occurs regardless of sexual orientation. In the 1998 landmark case that prompted a shift in legislation, a heterosexual male was harassed by other heterosexual males, not for sexual purposes, but to taunt him about his masculinity and body build. It is important to realize that this behavior is not always a sexual solicitation (Schleifer 2007).

\section{Sexual Harassment in Nontraditional Settings}

Non-traditional settings for sexual harassment include out-of-office scenarios, such as business trips, offsite meetings, restaurant visits, the Internet, or any other setting that is not the official workplace. In terms of the Internet, federal and state governments have enacted laws to protect individuals from online sexual harassment, which falls under the umbrella of "cyberstalking." Cyberstalking refers to any unwanted advances via the Internet. Here, anything sent or located in a shared folder or bookmarked on a public computer, such as offensive Web sites, inappropriate photos, or distasteful e-mails could be considered cyberstalking and, thus, Internet sexual harassment.

\section{Dealing with Sexual Harassment in the Information Age}

With ever increasing non-traditional sex discrimination, supervisors and managers need to ensure that the workplace is free from all types of harassment or prejudicial treatment (Zachary 1999). As a supervisor or manager, how should you react if you know nontraditional sexual harassment has occurred in your workplace? What is your role as a supervisor or manager? First, it is important to know that nontraditional and traditional sexual harassment are no different in terms of inappropriateness or severity. There is also no distinction, in terms of U.S. Federal law: they are both illegal.

However, apart from understanding, managerial action is needed to answer the issues of non-traditional sexual harassment. Here are some steps you can take to ensure your employees are informed on the matter of nontraditional sexual harassment, to prevent this type of harassment, and to encourage those who have been sexually harassed in this manner to come forward (EEOC 2008). 


\section{Step 1: Inform}

- Inform workers about their rights: Workers should understand the law, as well as their rights regarding nontraditional sexual harassment.

\section{- Speak candidly about nontraditional sexual} harassment: Workers should know the consequences of nontraditional sexual harassment, including legal and work-related implications (i.e., demotion, termination, etc.).

- Advise workers that sexual harassment, in any circumstance, is not okay: Sometimes it is vital to say things out loud, even the simplest messages. Remember, from the management perspective it is always better to give too much information than too little.

\section{Step 2: Prevent}

- Provide preventative training: Seminars and workshops would be ideal for nontraditional sexual harassment prevention. They would allow workers to be trained at length on the different forms of sexual harassment to more successfully identify and appropriately manage this type of behavior. Training could include printed materials and/or digital, computerized, or oral presentations. To enhance the effects of such training, participants should be required to pass a competency test on the subject or sign a nontraditional sexual harassment agreement. Training could be required for new hires or as annual workshops for all employees.

- Uphold the law: Make sure everyone who works for your company knows the different scenarios in which nontraditional sexual harassment can occur and how they may be prosecuted for breaking the law. This will help to reduce inappropriate behavior. Once you have explained the law and assured employees that the company will follow the law, make sure you follow through with disciplinary action if nontraditional sexual harassment occurs.

\section{Step 3: Encourage}

- Take action: If you witness nontraditional sexual harassment in the workplace or elsewhere by employees of your company, take immediate action. Follow company policy regarding "cease and desist" orders, warnings, or other forms of disciplinary action. If the harassment persists, follow through by enforcing the law and getting appropriate individuals in your organization involved.

\section{- Facilitate open communication with the} alleged offender: Do not immediately jump to conclusions regarding alleged nontraditional sexual harassment. Here is where management and leadership come into play. You must make educated decisions on how to proceed with both company policy and the law based on open communication with the victim and the harasser. Sometimes behavior, while inappropriate, does not constitute sexual harassment. Therefore, you must look at each complaint on a case-by-case basis. Sometimes open communication and mediation can solve problems before they escalate.

- Encourage resolution: Try to work out a resolution with the victim and harasser. Was this a misunderstanding? Is the harasser a repeat offender? These are questions you should ask before deciding how to react. If you deal with the situation effectively and immediately, you may save the company from legal action.

\section{Conclusions}

Human resource managers can more effectively combat nontraditional harassment behavior through knowledge and prevention. It is important that management recognize the different types of harassment and the scenarios in which they may occur. In situations where nontraditional sexual harassment has already taken place, managers should be equipped with the tools to mitigate and mediate the issue. Furthermore, all human resource managers should be trained in the areas of both traditional and nontraditional sexual harassment to respond to complaints in the best possible way. 
We hope you have found this article useful. We invite you to provide feedback (via e-mail) on which types of nontraditional sexual harassment were most prevalent in your organizations (Ms. Toomey: angelinactoomey@ufl.edu or Dr. Wysocki: wysocki@ufl.edu). Your comments and suggestions are always welcomed.

\section{Resources}

\section{The U.S. Equal Employment Opportunity Commission}

- Sexual Harassment: http://www.eeoc.gov/types/ sexual harassment.html

- Facts about Sexual Harassment: http://www.eeoc.gov/facts/fs-sex.html

\section{Sexual Harassment Prevention Center}

- The SHP Center Homepage: http://stopharass.com/

- A New Era in Sexual Harassment: http://stopharass.com/article-sexual$\underline{\text { harassment.htm }}$

\section{Same Gender Sexual Harassment}

- Is it sex discrimination under Title VII? http://heinonline.org/HOL/ Page?handle $=$ hein.journals $/$ $\underline{\text { saclr36\&div }=52 \& \mathrm{~g} \text { sent }=1 \& \text { collection }=\text { journals }}$

\section{Sexual Harassment Legal Info Center}

- SHLI Center Homepage: http://sexualharassment.com/

\section{American Bar Association: Practical Law}

- The Law \& Your Job - Sexual Harassment: http://www.abanet.org/publiced/practical/ sexualharassment.html

\section{References}

Barak. A. 2005. Sexual harassment on the Internet. Social Science Computer Review (23):1. http://ssc.sagepub.com/
Gross, J. 1995. Ideas \& trends; Now look who's taunting. Now look who's suing. The New York Times (electronic version). http://query.nytimes.com/gst/ fullpage.html?res=990CE6DD1430F935A15751C0A $963958260 \& \mathrm{sec}=$ \&pagewanted $=2$

Schleifer, J. 2007. Nontraditional sex harassment cases on the increase. HR Daily Adivsor. http://hrdailyadvisor.blr.com/archive/2007/06/20/ Same sex gender sexual harassment workplace.asp $\underline{\mathrm{X}}$

United States Army Combined Arms Support Command. No Date. Complaint procedures. U.S. Army, Washington, D.C. http://www.cascom.army.mil/EO/ complaint $\% 20$ Procedures.htm

United States Equal Employment Opportunity Commission. 2008. Sexual harassment. EEOC, Washington, D.C. (February 11). http://www.eeoc.gov/types/sexual harassment.html

Zachary, M.K. 1999. Labor law for supervisors: 'Because of sex' - the non-traditional cases. EBSCO Host Research Databases. http://web.ebscohost.com.lp.hscl.ufl.edu/ehost/ detail?vid=1\&hid=105\&sid=3cfleec8-3010-450d9332-38ba414636f4\%40sessionmgr106 